\title{
PROJETO ALADIM: JOGOS DIGITAIS E NOVAS INTERFACES PARA ALFABETIZAÇÃO
}

\author{
ALADDIN PROJECT: DIGITAL GAMES AND NEW INTERFACES FOR LITERACY
}

Carla Viana Coscarelli ${ }^{1}$

\begin{abstract}
RESUMO
Apresentamos aqui algumas atividades e resultados de pesquisas realizadas pelos participantes do Projeto Aladim (UFMG). Esse projeto tem como objetivo analisar jogos voltados para a alfabetização, disponíveis na Internet e no mercado, além de, buscar pesquisar e desenvolver jogos em novas interfaces como mesa multitoque e visão computacional. Neste artigo, são apresentados resultados de análises de jogos para alfabetização encontrados na Internet, bem como em jogos como Coelho Sabido, Arthur e Laptop da Xuxa. Apresentamos também jogos que estamos desenvolvendo em interfaces tradicionais, como o Papaletras e o Tiroletras, baseados respectivamente no Pacman e no Space Invaders. Além disso, mencionamos outras interfaces utilizando mesa multitoque e visão computacional que temos buscado explorar nesse projeto.
\end{abstract}

Palavras-chave: Jogos. Alfabetização. Novas interfaces.

\begin{abstract}
We present some activities and results of research produced by participants of the so-called "Aladdin Project" (UFMG). The project's aim is to analyze games available both on the Internet and market, for children who are being literate. Besides that, we try to research and develop our games, by using new interfaces such as multitouch screen and computer vision technology. We briefly present results of those analyses, as well as the games we are developing, using traditional interfaces, multi-touch screen, and computer vision that we have been trying to explore.
\end{abstract}

Keywords: Games. Literacy. New interfaces.

\section{INTRODUÇÃO}

O ALADIM (Alfabetização e Letramento em Ambientes Digitais Multimodais) é um projeto que conta com a participação de uma equipe interdisciplinar composta por professores e alunos dos cursos de Belas Artes, Computação, Games, Letras e Pedagogia. Tem como objetivo principal criar jogos digitais para auxiliar a alfabetização e o letramento digital.

\footnotetext{
${ }^{1}$ Universidade Federal de Minas Gerais - UFMG. Email: cvcosc@yahoo.com.br
} 
Essa equipe tem analisado tanto jogos que podem ser encontrados no mercado, quanto aqueles que estão disponíveis na Internet, a fim de fazer um levantamento do que já está disponível e de como esses materiais lidam com os conteúdos da alfabetização e como se utilizam da tecnologia para desenvolver habilidades de leitura e escrita nos jogadores. Até o momento já foi possível verificar (Ribeiro e Coscarelli, 2009) que a concepção de aprendizagem que lhes serve de base é muito behaviorista, ou seja, o jogo indica para o aluno apenas se ele acertou ou errou, mas não fornece nenhum feedback para que ele compreenda o seu erro ou para ajudá-lo a acertar na próxima vez. Não há uma organização das habilidades e conteúdos trabalhados nos jogos e, em sua maioria, esses jogos são apenas uma transposição das atividades tradicionais feitas no papel para a tela do computador. Isso representa um desperdício de tecnologia, além de refletir o fato de que, provavelmente, não há educadores e linguistas envolvidos na elaboração desses jogos.

Paralelamente à análise de jogos, trabalhamos na criação de novas interfaces que não lidam com o mouse e o teclado, trabalhando com telas multitouch e capturas em webcam. Essas tecnologias permitem que a criança participe fisicamente dos jogos, tendo de correr para pegar sílabas ou movimentar os braços para ajuntar letras, por exemplo, tornando a participação dela mais dinâmica e agradável do que nas interfaces tradicionais como a tela, o teclado e o mouse. Com a exploração dessas interfaces, pretendemos colocar em prática a proposta feita por Gee (2003) de desenvolver jogos com fins educacionais que se sustentam em três pilares teóricos. Um deles é o trabalho sobre cognição situada (corporificada / contextualizada), em que a cognição é pensada não apenas como o que acontece no cérebro do indivíduo, mas sendo ligada a um corpo que interage com um mundo material, social e cultural. O outro pilar são os estudos dos novos estudos sobre o letramento (New Literacy Studies) de acordo com os quais a leitura e a escrita devem ser vistas como processos mentais, mas também como processos sociais e culturais. O terceiro pilar é o conexionismo, que enfatiza o poder do ser humano de reconhecer padrões, ou seja, os seres humanos nem sempre têm as melhores ideias ou soluções quando raciocinam via lógica, "ao contrário, eles pensam melhor quando raciocinam com base em padrões depreendidos de suas experiências reais com o mundo, padrões esses que podem ser generalizados, mas que têm raízes em áreas específicas da experiência" (Gee, 2003, p. 8).

Além da criação de novas interfaces, estamos criando jogos de alfabetização baseados em tecnologia mais tradicional de criação de games como jogos de plataforma e isométricos, a exemplo de jogos como Mário, Zelda, Pacman, entre outros. 
Esse trabalho tem gerado estudos e discussões interdisciplinares ricas, integrando tópicos importantes para a criação de jogos e a reflexão sobre eles, envolvendo os conceitos de letramento, alfabetização, ensino/aprendizagem, games e tecnologias.

Pretendemos, neste artigo, apresentar alguns resultados de pesquisas realizadas pelo ALADIM, bem como jogos e interfaces nos quais temos trabalhado.

\section{ANÁLISE DE JOGOS DE ALFABETIZAÇÃO DISPONÍVEIS NA INTERNET}

Numa análise de jogos de alfabetização disponíveis gratuitamente em português pudemos verificar que não há muitas opções interessantes de sites voltados para a alfabetização na Internet.

Analisando vários aspectos desses jogos, a saber: interface e instruções, feedback, concepção de aprendizagem, contextualização, repertório linguístico, recursos, tarefas, recompensa, desafio, funcionamento do jogo, pudemos observar que os jogos não atendem bem a vários desses quesitos ${ }^{2}$.

Os jogos deixam a desejar por a concepção de aprendizagem da maioria desses jogos é behaviorista, ou seja, há uma indicação para o jogador de que ele acertou ou errou, mas não há feedback suficiente para que ele compreenda o seu erro, nem que sirva de orientação para que ele seja capaz de acertar numa outra jogada.

Nem sempre é fácil identificar os conteúdos e as habilidades trabalhados nos jogos, e normalmente as atividades lidam com letras, sílabas ou palavras, raramente lidando com parágrafos, textos, suportes ou situações contextualizadas de leitura e escrita.

Os jogos costumam ser apenas uma transposição de atividades que podem ser encontradas ou feitas no impresso para a tela do computador, e não exploram os recursos tecnológicos disponíveis atualmente.

As tarefas são normalmente repetitivas e o repertório linguístico (letras, sílabas ou palavras) explorado nos jogos é reduzido, não havendo na maioria das vezes uma organização clara dos conteúdos por grau de dificuldade ou algum outro critério que revele a concepções linguísticas motivou as escolhas do repertório ou sequência.

Nesses jogos, os jogadores não recebem recompensas, prêmios, vidas, assim como também não correm riscos, não perdem vidas, entre outros desafios e motivações que atraem e motivam os jogadores.

\footnotetext{
${ }^{2}$ Mais detalhes sobre estas análises podem ser encontrados em Ribeiro e Coscarelli, 2009
} 


\section{ANÁLISE DE JOGOS DE ALFABETIZAÇÃO DISPONÍVEIS NO MERCADO}

Entre os programas disponíveis no mercado que têm como objetivo auxiliar a alfabetização, analisamos o lap top da Xuxa, o Coelho Sabido e Arthur.

\section{Laptop}

No laptop da Xuxa, analisamos as atividades que se relacionam à aquisição da escrita (Araújo e Curto, 2008). O laptop possui uma tela pequena que apresenta imagens sem cores e pouco atraentes, sendo uma interface pouco estimulante. Não há uma narrativa que subsidia os jogos, que, na verdade, são atividades que têm como elo apenas o campo semântico das palavras que aparecem (ex. animais, transporte, objetos da casa, profissões e lugares, corpo e movimento) e a tarefa que o jogador tem de realizar (colocar as letras em ordem, reconhecer o nome do animal que apareceu na imagem, escrever o nome da imagem que apareceu na tela, descobrir a letra que não faz parte da palavra).

As capacidades trabalhadas concentram-se em reconhecer a relação fonema/grafema e dominar as convenções ortográficas. Todos os seus jogos limitam-se à estrutura da palavra, funcionando à base do estímuloresposta, isto é, para acertos, somam-se pontos e tem-se um reforço sonoro ("Excelente!"); para "erros", advertência automática (“Opa! Tente novamente!"), pontuação inalterada (ou em valor menor) e possibilidade de recomeçar a atividade. (ARAÚJO E CURTO, 2005, p.5)

Esse feedback indica para o jogador se ele acertou ou errou, mas não contribui para que ele saiba por que errou e como acertar, contribuindo pouco para a aprendizagem do jogador.

Os jogos não apresentam desafio para o jogador uma vez que há pouca variação nos níveis de dificuldade das atividades, não há surpresas, nem novos desafios e não há possibilidades de fazer trajetos diferenciados, já que o programa apresenta a sequência de palavras de cada atividade. O sistema de recompensa se baseia numa pontuação cujo valor máximo é 100 pontos. Uma vez que o jogador completa esse total, a atividade acaba e é oferecida ao jogador a chance de repetir o jogo. 
Esse jogo não realiza a contento nem o quesito jogo, diversão, nem o quesito educação.

\section{Coelho Sabido}

Esse jogo faz parte de uma coleção de CDs cada um voltado para uma faixa etária específica. $\mathrm{O} C \mathrm{CD}$ que analisamos tem como público-alvo alunos de primeira série do ensino fundamental.

O Coelho Sabido é ambientado em uma floresta e parte de uma narrativa adequada à faixa etária. A criança tem como missão, ajudar na reconstrução de um espetáculo teatral boicotado por um vilão. O objetivo do jogo é alcançado quando o jogador reúne todos os itens necessários para a exibição do espetáculo, que é então apresentado.

O jogo apresenta atividades de diferentes áreas do ensino: português, matemática e ciências, e procura desenvolver diversas habilidades. No que concerne à aquisição do sistema de escrita, há atividades que lidam com a relação grafema e fonema bem como atividades que trabalham com textos (ex. roteiro de teatro). Não há ordem fixa para a realização das atividades, e a criança pode realizar vários percursos para cumprir o objetivo. Além disso, o jogador tem a liberdade de parar o jogo e retornar, em outro momento, do ponto onde parou.

Existe nas atividades preocupação constante em oferecer feedback rico o suficiente para que o jogador consiga compreender seu erro e ser melhor sucedido numa outra tentativa (ex. "Sinto dizer, mas preciso explicar: a tartaruga sábado fica em outro lugar."; "Acho que não é bem isso. Nove é diferente de nave! Escolha a letra certa para passar pela minha porta."; "Hum... acho que não... a palavra navio não combina com a frase... Leia a frase novamente e escolha outra palavra."). Respostas positivas que reforçam a ação do jogador também são uma constante no jogo.

Em suma, podemos dizer que o Coelho Sabido, une, de forma eficiente o entretenimento e o ensino. Nas palavras de Araújo e Curto (2008)

através de uma narrativa envolvente, oferece desafios estimulantes que promovem uma interação efetiva do jogador. A existência de um objetivo a ser cumprido (reunir os itens para a apresentação do show), apoiado em um enredo e personagens bem construídos, orienta o jogador no seu percurso pelo game e o leva a explorar os caminhos oferecidos em um cenário interessante, colorido e autoexplicativo. A previsibilidade de alguns rumos do jogo se mescla às surpresas que aguardam o jogador na 
realização de suas tarefas. A cada missão cumprida, o jogador é pontuado indiretamente através da obtenção dos itens necessários para a apresentação da peça de teatro, fazendo com que sua pontuação não seja algo cumulativo e descontextualizado. O jogo promove o desenvolvimento de variadas habilidades do jogador por meio de tarefas desafiadoras, educativas e lúdicas (p.9).

Arthur e um dia de trabalho dos pais

Arthur e um dia de trabalho dos pais é um software educativo em CDRom, analisado por Frade et al. (2009), que tem como público alvo estudantes do segundo ano do Ensino Fundamental É jogo criativo e de caráter multidisciplinar, mas apresenta algumas lacunas em aspectos importantes para a etapa da alfabetização a que se destina. No entanto, cumpre a função de ensinar ludicamente.

No jogo, Arthur e seus amigos desejam conhecer e executar o trabalho de seus pais e conquistam um certificado quando conseguem realizar essas tarefas.

Há diferentes níveis de dificuldades no jogo e, nas partes que se voltam para a alfabetização, pode se notar complexificação nos aspectos ortográficos, na formação das sentenças, e a presença de pequenos textos.

As animações são coloridas e o jogo é visualmente atraente. Há muita exploração das linguagens áudio e visual, o que parecer ser uma boa estratégia em jogos voltados para a alfabetização.

No que diz respeito à concepção de aprendizagem adotada, pode-se dizer que o jogo tem uma forte base behaviorista de aprendizagem. Muitas atividades exigem memorização e, por isso, atividades que trabalham a repetição são frequentes. Por outro lado, há situações em que o jogador deve usar pistas para resolver os problemas de escrita, o que sugere uma concepção de aprendizagem construcionista em algumas situações do jogo.

O jogo busca integrar conceitos de alfabetização, letramento e letramento digital, procurando trabalhar elementos da alfabetização na perspectiva do uso social da língua.

Há várias etapas a serem cumpridas, cada uma delas com três níveis de dificuldade. O jogador precisa cumprir os desafios de todas as etapas para obter o certificado, que é o objetivo final do jogo.

Esse jogo não pode ser considerado ideal, mas representa um avanço em relação à maioria dos jogos educativos disponíveis na Internet e no mercado. Frade et al. (2009) terminam a análise desse jogo levantando uma questão com a qual concordamos e sobre a qual temos procurado discutir: 
A análise de Arthur e um dia de trabalho dos pais remete à urgência de os educadores voltarem o olhar para o campo dos jogos educativos. Há ainda nesse campo uma considerável escassez de elementos que se debrucem verdadeiramente sobre um caráter educativo e uma falta ainda maior daqueles que o fazem de forma excelente associando educação e ludicidade.

Como pudemos notar nas análises dos jogos disponíveis gratuitamente na Internet e em jogos disponíveis no mercado, não há muitas opções de jogos que lidam a contento com a alfabetização e que trabalhem bem tanto com a dimensão lúdica quando com a dimensão educativa, sendo essa uma lacuna que precisa ser preenchida. Passaremos a apresentar a seguir alguns jogos e interfaces que temos procurado desenvolver no Projeto Aladim. É importante esclarecer, que como o nosso objetivo principal é a pesquisa, não estamos desenvolvendo esses jogos e interfaces com fins comerciais e sim com o objetivo de desenvolver conhecimento e tecnologia que possam ser usados para desenvolvimento de jogos comerciais.

\section{JOGOS E INTERFACES EXPLORADOS NO ALADIM}

No Projeto Aladim temos nos preocupado em desenvolver jogos de plataforma ou jogos isométricos, a exemplo de jogos como Mário, Zelda, Pacman, e que rodam em PCs.

Como exemplo de jogo baseado em jogos tradicionais, temos o Papaletras que é baseado no famoso Pacman. O jogo se passa em labirintos, onde o jogador deve esquivar-se de monstros e coletar as sílabas corretas para formar a palavra representada pelo desenho no centro da tela. Ao tocar uma sílaba correta, isto é, que compõe a palavra apresentada como objetivo, os monstros se tornam vulneráveis, permitindo ao jogador derrotá-los temporariamente adquirindo assim mais pontos. Quando todas as sílabas necessárias para a escrita da palavra-objetivo forem coletadas, o jogador avança para o nível seguinte, aumentando assim a dificuldade do jogo em função de tempo de experiência (Rabin, 2005). Pretendemos desenvolver vários níveis para esse jogo, lidando não só com sílabas, mas também com palavras, letras e frases. 
A interface exibe apenas a pontuação e o número de vidas restantes, exibidas na barra da janela. Cada sílaba correta que é coletada pelo jogador se desloca para o canto superior direito da tela, informando ao jogador sua progressão naquele estágio. Elementos como progressão da dificuldade, clareza de objetivos, possibilidade de conclusão ou não do jogo, entre outros, tornam a atividade mais próxima da vivenciada em um jogo comercial, sendo, portanto mais atrativa e desafiadora do que a grande parte dos jogos educativos disponíveis atualmente. O jogo proporciona ao jogador a chance de aplicar e testar conhecimentos adquiridos, servindo assim como complemento para a alfabetização escolar, uma vez que desenvolve a interpretação de figuras e o uso dos elementos gráficos usados para representá-la e vice-versa (COSTA, COSCARELLI e DALLAPÍCULA, 2008)

Ainda estamos estudando formas de oferecer instruções e feedback que sejam ricos o suficiente para ajudar o jogador a refletir sobre suas estratégias de jogo, sobre seus erros e a descobrir o que fazer para acertar (aprender). Numa variante do Pacman, criada por Borges (2013), testamos dois tipos de instrução: a instrução explícita e implícita.

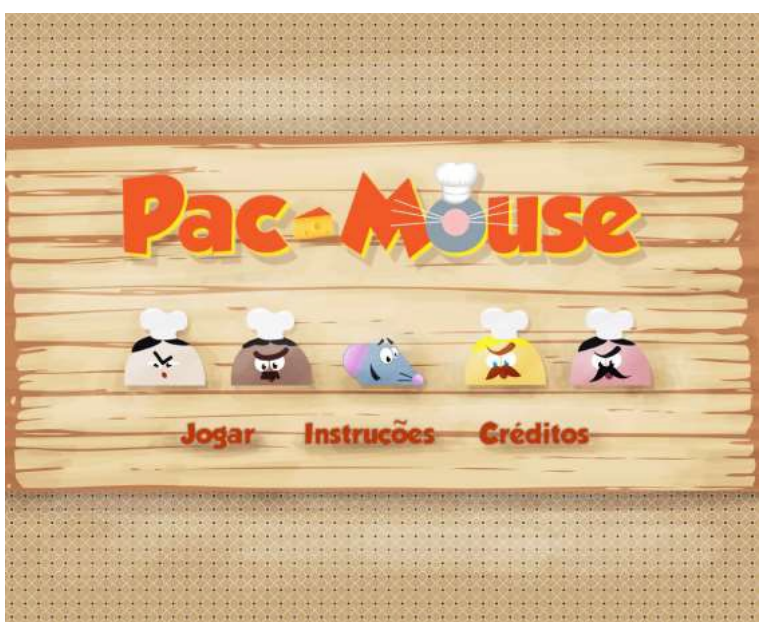

Figura 1: Tela inicial do jogo Pac-Mouse (Borges, 2013, p.65)

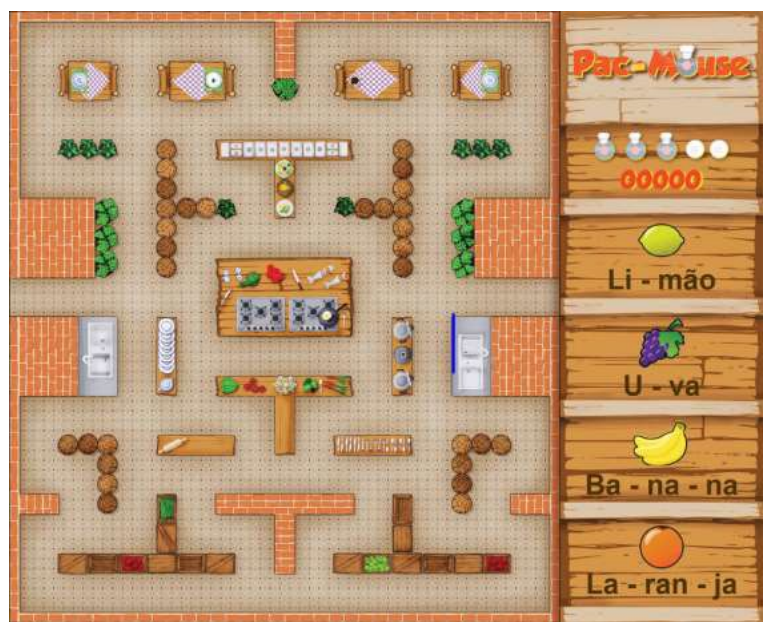

Figura 2:Ambiente do jogo Pac-Mouse (Borges, 2013, p.67)

Este jogo se passa em uma cozinha em que o rato quer pegar alimentos (sílabas de nomes de frutas) e os cozinheiros tentam impedir que ele consiga alcançar as sílabas e assim conseguir comer as frutas. A versão com instrução explícita continha informações que orientavam o jogador sobre os procedimentos necessários para formar as palavras. Já o jogo com instruções implícitas não apresentava orientações sobre a ordem que as sílabas deveriam ser comidas. A 
versão que obteve mais repetibilidade e que, portanto, contribuiu mais para os jogadorem aperfeiçoarem o desempenho no jogo foi a de instruções implícita.

Para quem jogou a versão implícita, o que indicava a ordem correta [para pegar as sílabas] era a cor. A primeira sílaba a ser comida tinha a cor mais clara. Então, o testar de sílabas, tal e qual acontecia com os jogadores da versão explícita, nesse caso, resultava na aprendizagem da ordem correta porque foi percebido que a cor informava. Isso facilitou a curva de aprendizagem. Sendo assim, os jogadores da versão implícita se atinham ao desafio proposto no Pac-Mouse, que era fugir de quatro cozinheiros que possuíam comportamentos diferentes e criavam situações diversificadas de perseguição. Esses desafios eram elementos importantes para gerar a repetibilidade, pois, mesmo que a criança soubesse a ordem das palavras, isso não significava que ela teria facilidades para vencer cada fase e, consequentemente, o jogo. Era necessário desenvolver habilidades para não perder vidas que lhe levassem à morte no jogo e ainda traçar estratégias para enganar os cozinheiros, durante as perseguições, para que as sílabas pudessem ser pegas. (BORGES, 2013, p. 144)

Além destes jogos, estamos desenvolvendo também o Tiroletras que é inspirado no Space Invaders e no Frozen Bubble. Do Space Invaders, tiramos a ideia de movimentação do jogador e as bombas sendo atiradas nele e por ele. Do Frozen Bubble, retiramos a ideia de o jogador ter a possibilidade de escolher mais de uma opção de tiro. No Tiroletras o jogador tem de atirar em letras para formar palavras.

Ao invés de uma série de inimigos totalmente aleatória, a frota do nosso inimigo é sempre uma palavra. Palavras com menos letras representam os primeiros níveis e palavras com mais letras representam níveis mais elevados. Assim, o jogador deve acertar um inimigo representado por uma letra com um tiro com aquela mesma letra, ou seja, um inimigo representado pela letra $A$ soltará bombas também representadas pela letra $A$ e, para destruí-la, o jogador deve realizar um tiro com a letra $A$ que a acerte. Vale ressaltar que o jogador deve desviar das bombas lançadas pelos seus inimigos como no Space Invaders. O jogador é controlado pelo mouse. Movendo o mouse, move-se o jogador, clicando com o botão esquerdo atira-se e com o botão direito muda-se a opção de letra para o próximo tiro. (SANTOS, 2009) 
Pretendemos desenvolver esse jogo oferecendo ao jogador uma situação em que os elementos linguísticos que vão fazer parte do jogo sejam explorados de forma contextualizada. Como, por exemplo, um garoto precisa atravessar a floresta para encontrar sua irmã que está perdida e, para isso, tem de preparar uma mochila com os objetos de que pode precisar. Esses objetos que vão compor a mochila serão conquistados nos jogos. Muitas situações vão fazendo parte de uma narrativa maior que terá muitos desafios linguísticos para os jogadores.

\section{NOVAS INTERFACES}

Além dos jogos tradicionais, estamos pesquisando novas interfaces como uma mesa multitoque e multiusuário para o desenvolvimento de jogos, em que dispositivos de entrada como o mouse e o teclado são substituídos pela interação direta das mãos com a superfície onde os elementos gráficos são mostrados.

Procuramos também desenvolver jogos usando visão computacional para a captura de gestos, a fim de explorar modos de interação entre a criança e o computador baseados em gestos e movimentos. Acreditamos que esse modo de interação com o computador por meio do movimento corporal possibilita uma interação socializada, uma vez que permite a ação conjunta de mais de uma criança, e natural, pois permite que a criança se manifeste com a gestualidade característica de sua idade.

Um exemplo disso é o jogo "Piracema" (criado por Francisco Marinho e Álvaro Garcia), apresentado no espaço Israel Pinheiro em Brasília em outubro de 2009, que, embora não utilizasse linguagem verbal, exigia a ação dos participantes, que muitas vezes agiam colaborativamente para realizar a tarefa de ajudar os peixes a desviarem do lixo para subir o rio. A interface usada é uma câmera que capta as imagens das crianças e as insere dentro do ambiente virtual, dando a elas o poder de interferir na rota e nos movimentos dos peixes. Estamos planejando formas de usar essa tecnologia, entre outras, a fim de ajudar os participantes a construir e compreender o sistema linguístico, bem como outros sistemas semióticos que atuam junto a ele, de forma lúdica, reflexiva e colaborativa.

Para satisfazer aos nossos objetivos com esse projeto, consideramos essencial que as interfaces sejam de baixo custo e possam ser utilizadas simultaneamente por um pequeno 
grupo de alunos. Para tanto buscamos a utilização de dispositivos de baixo custo, bem como software livres e tecnologias abertas.

\section{CONSIDERAÇÕES FINAIS}

Estamos trabalhando para que, em breve, tenhamos mais jogos e interfaces prontos para serem testados em alunos na fase de alfabetização. Há muita tecnologia disponível que pode e deveria ser usada para auxiliar a aprendizagem, seja da escrita ou de outros conteúdos, mas isso não é tarefa de apenas um programador de jogos, ou de um especialista em educação ou letras, mas de uma equipe multidisciplinar que discuta as bases teóricas da criação desses jogos com fins educacionais. É este trabalho que estamos tentando desenvolver.

Acreditamos que o projeto ALADIM vai trazer boas contribuições teóricas e práticas a cerca da informática na educação e, mais especialmente, na alfabetização.

\section{REFERÊNCIAS}

AraúJo, Francys S. e Curto, Viviane G. Capacidades em jogos infantis: a alfabetização em ambientes digitais. In: Anais do SBGames 2008 (CD). PUC/MG, UFMG, Belo Horizonte.

Borges, Anderson Pimentel. Jogo digital para reconhecimento de palavras: análise comparativa entre as versões com instruções implícitas e explícitas. FALE/UFMG, Belo Horizonte, 2013. (Tese de doutorado).

Costa, Lucas Gonçalves; Coscarelli, Carla Viana; Dallapícula, Valério. Jogos e alfabetização: analisando a prática. In: Anais do SBGames 2008 (CD). PUC/MG, UFMG, Belo Horizonte.

Frade, Isabel, TAKenaKA, Camila, RAmalho, Bárbara. As potencialidades e limites de um software que trabalha conteúdos da alfabetização. Trabalho apresentado no III Encontro Nacional sobre Hipertexto 2009, CEFET-MG, Belo Horizonte, 2009. 
GEE, James Paul. What video games have to teach us about learning and literacy. New York, Palgrave Macmillan, 2004.

RABIN, Steve. Introduction to game development. USA: Charles River Media, 2005.

Ribeiro, Andréa Lourdes; Coscarelli, Carla Viana. Jogos online para alfabetização: o que a internet oferece hoje. Trabalho apresentado no III Encontro Nacional sobre Hipertexto 2009, CEFET-MG, Belo Horizonte, 2009. Disponível em https://www.ufpe.br/nehte/hipertexto2009/anais/g-1/jogos-online.pdf

SAnTos, Bruno. Relatório de atividades de bolsista da Proex. Belo Horizonte, FALE/UFMG, 2009. (mimeo.)

RECEBIDO EM: 04/09/2012

APROVADO PARA PUBLICAÇÃO EM: 14/09/2015 